\title{
ЗНАНИЯ, КОМУНИКАЦИЯ С МЕДИЦИНСКИТЕ СПЕЦИАЛИСТИ И НАГЛАСИ ЗА ЯВЯВАНЕ НА ПРЕГЛЕД СРЕД ГРАЖДАНИ, ПОДЛЕЖАЩИ НА ОНКОЛОГИЧЕН СКРИНИНГ
}

\author{
Ю. Панайотова, Л. Георгиева
}

\author{
KNOWLEDGE, COMMUNICATION WITH MEDICAL PROFESSIONALS \\ AND ATTITUDES TO MEDICAL EXAMINATION AMONG PEOPLE \\ SUBJECT TO ONCOLOGICAL SCREENING
}

\author{
U. Panayotova, L. Georgieva
}

\begin{abstract}
Рез юме. Онкологичният скрининг е една от мерките за контрол на раковите заболявания. Въвеждането на програми с широк обхват може да доведе до значително намаляване на смъртността и заболяемостта, ако се спазват критериите за качество. В България скринингът е опортюнистичен, несистемен и неефективен. Цел: Да се проследят знанията и нагласите за явяване на преглед сред подлежащи на иервикален, мамографски и колоректаклен скрининг лица, както и оиенката им за комуникацията с медииинските специалисти, ангажирани с превениията на рака в България. Методи: Анкетирани са 300 граждани на възраст над 25 години, разпределени в три групи според скрининговата локализация. Данните са събрани през месеи май 2018 г. чрез стандартизирани интервюта в дома на респондентите. Резултати: Знанията за скрининговите тестове и изследвания сред гражданите са недостатъчни и се различават значително за различните локализачии. Медииинските специалисти не предоставят достатьчна информачия относно ползите и рисковете от скрининговите изследвания. Сред гражданите преобладават позитивните нагласи за явяване на скрининг, като препоръката от лекар е предпочитана пред писмената покана. Заключение: Необходими са постоянни усилия за повишаване информационното ниво и знанието относно скрининговите изследвания, тяхната същност и иели. Нужно е разработване на алгоритми и указания към медицицинскте специиалисти провеждащи скринингови прегледи, както и унифицирана документация.
\end{abstract}

S u $\boldsymbol{m}$ m a ry. Oncological screening is one of the measures to control cancer. The introduction of population-based screening programs can lead to a significant reduction in mortality and morbidity, if the quality criteria are met. In Bulgaria, screening is opportunistic, unsystematic and ineffective. Purpose: To explore the knowledge and attitudes for attending screening tests, among cervical, mammographic and colorectal screening subjects as well as their assessment of communication with medical professionals involved in cancer prevention in Bulgaria. Methods: 300 citizens over the age of 25 were interviewed, divided into three groups according to the screening location. The data were collected in May 2018 through standardized interviews at the respondents' home. Results: The knowledge about screening tests among citizens is insufficient and varies greatly for different locations. Medical professionals do not provide sufficient information on the benefits and risks from screening tests. Among the citizens, positive attitudes to screening prevail, with the recommendation given from a doctor being preferred to the written invitation. Conclusion: Continuous efforts are needed to raise the information level and knowledge about screening studies, their nature and objectives. It is necessary to develop algorithms and guidelines for medical professionals conducting screening as well as unified documentation.

Key words: oncological screening, knowledge, attitudes, barriers, communication

3

локачествените заболявания са сред най-честите социално значими заболявания, както в света, така и в България (Bray et al. 2018). Голяма част от тях могат да бъдат предотвратени чрез превенция и профилактика. Възприемането на по-здравословен начин на живот и въвеждането на организиран популационен скрининг с широк обхват могат да доведат до значително понижение на броя заболелите и до съществено намаляване на разходите за лечение и палиативни грижи. Едно от основните предизвикателствата при въвеждане на национални скринингови програми е, необходимостта от координирани усилия на много нива в здравната система, за да се гарантира качеството на услугите и ефективността на програмата. Невъзможността за осигуряване на дългосрочна устойчивост е сред най-големите рискове.

За да има най-голяма полза и най-малко вреди от скрининга, предоставяните услуги трябва да бъдат с възможно най-високо качество. Спазването на основните принципи (Wilson \& Jungner, WHO,1968) и придържането към Европейските насоки за гарантиране на качеството при скрининг за рак (Arbyn et al. 2008; Pery et al. 2010; Atkin et al. 2012), могат да спомогнат за постигане на висок обхват и ефективност на националните програми.

Докато ефективността на програмата може да се осигури с добра организация и контрол, то субективното усещане на гражданите за качеството на предложените им по време на скрининг услуги не е постоянно и следва да се изследва регулярно. Един от най-важните фактори за успеха на програмата е нагласата за участие в бъдеще, която е в пряка зависимост от опита при предишни (скринингови) прегледи и изследвания.

В страните, в които скринингът е държавна политика, едни от основните индикатори за успех, са големия брой явили се за изследване (обхват) и готовността на преминалите през скрининг за явяване и в бъдеще. За постигането на високи нива на двата индикатора, е необходима балансирана информация за ползите и потенциалните опасности и вреди, както и постоянна оценка на мотивиращите фактори и бариерите, повлияни от получената информация. Описанието предимно на ползите от скрининга, може да доведе до висок обхват при първа покана, а „премълчаната” информация за рисковете - до негативни изживявания по време на прегледа и разколебаване на готовността за участие в бъдеще.

Субективното разбиране за качество на предлаганата здравна информация зависи от достоверността на източника, образователното ниво на потребителите ѝ и разбирането за нейната ценност.

Интегрираният подход към превенцията и контрола на раковите заболявания неотменно включва и ефективен диалог между лекар и пациент. Поставянето на пациента в центъра на диагностичния и лечебния процес го превръща в активен участник при взимането на решения. Съгласно насоките за качествено провеждане на скрининг, получаването 
и обсъждането на резултатите е съществен елемент, определящ нагласите на изследваните лица за явяване на следващо скринингово изследване в бъдеще. Независимо че по-новите указания за оценка на качеството при скрининг препоръчват изпращането на резултатите от изследването по пощата, съобщаването по телефон или получаване на място също са възможни решения.

Въпросът за комуникацията между подлежащите на скрининг и медицинския персонал, както и по-общо, между лекари и пациенти, е силно подценяван в нашата здравна система. Комуникационните умения се считат за второстепенни. Данните от представените изследвания показват, че у нас няма ясни указания каква информация се очаква от лекарите и медицинските специалисти, предоставящи скринингови услуги (Аврамова и кол. 2005; Valerianova et al. 2010). Обикновено лекарите предоставят „техническа“ информация за процедурата, резултатите от цитонамазките, необходимите последващи действия, пренебрегвайки обсъждането на същността, ползите и рисковете от скрининга. Често медицинските специалисти считат, че не е тяхна отговорност да предоставят на пациентите подробна информация за рака и неговата профилактика и виждат това като периферна дейност, която трябва да се извършва от институции за здравна просвета и граждански организации извън здравната система (Аврамова и кол, 2005; Todorova et al. 2009; Valerianova et al. 2010).

Съществен елемент от стратегиите за въвеждане на скрининг е познаването на нагласите на лицата за явяване при покана, както и бариерите пред този избор (Todorova I et al. 2006; Craciun, C et al. 2018). Познаването на факторите, препятстващи гражданите при взимане на решение за явяване на преглед, може да спомогне за разработване на дейности и материали, които да улеснят избора им и да помогнат за по-доброто отзоваване при покана (Гергов 2016; Димова Р, Димов Р., 2007; Джафер 2015) .

Сред факторите, определящи нагласите за редовно явяване на скринингови прегледи са удовлетвореността на преминалите през изследване лица от предоставените услуги и усещането им за лична ефективност. Оценката на удовлетвореността на участниците е част от общата оценка на качеството на скрининговите услуги (Peipins L et al. 2006; Tang T et al. 2009). Елементите, определящи чувството за удовлетвореност са: достьпността на услугата, информацията, получена преди прегледа, изпитаният физически дискомфорт и/или болка, усещането за психическо безпокойство, комуникационните умения на персонала, физическите условия (среда, апаратура, достъп), начинът на съобщаване на резултатите и др. Разбирането на общите и специфичните детерминанти на удовлетвореността позволява идентифициране и решаване на проблеми, което от своя страна може да доведе и подобряване на услугата. Това е особено важно в националните организирани програми, където високото качество трябва да се запази за дълъг период от време във всички звена, предлагащи изследвания и за всички слоеве от населението (Gabel et al. 2017; Almog et al., 2008).

\section{Методика}

В изследването участват 256 жени и 44 мъже. Мъжете са около половината от лицата в проучването за колоректален рак. Участниците са разпределени в три групи и са анкетирани за конкретна скринингова локализация: рак на маточнта шийка (РМШ), рак на млечната жлеза (РМЖ), колоректален рак (КРР). Възрастовият диапазон на всяка група е в съответствие с европейските и национални препорьки - 25-59 г. за цервикален скрининг, 45-69 за мамографски скрининг и лица над 50 години за колоректален. По 100 представители за всяка група са селектирани по възрст, населено място, образование и етнос. Извадката включва жители на София, Бургас, Плевен, Перник и Стара Загора), както и на села от областите Перник и Плевен. Изследването е проведено през м. май 2018 година, като е използвана случайна гнездова извадка от мрежата на социологическа агенция „Сова-5“ АД. Анкетирането е проведено в домовете на респондентите.

\section{Резултати}

Според местоживеенето си, над половината от участниците са от столицата (58.33\%), около една трета от областни градове $(33 \%)$ и една четвърт живеят в села $(25 \%)$. Над две трети от участниците живеят в брак или съвместно съжителство, а около една четвърт са неженени, разведени или вдов(и)ци. Заявената етническа принадлежност на анкетираните е предимно българска, като около осем процента са се самоопределили като лица от турски или ромски етнос. Според образователната си степен, около половината от участниците са със средно образование, а една трета - с висше. Останалите са със степен по-ниска от средно образование или без никакво образование. Над десет процента от анкетираните са били безработни в периода на изследването, около две трети - служители и над двадесет процента - пенсионери.

\section{Знания}

Сравнението на знанията за трите изследвания показват най-добра информираност по отношение на цитонамазките (Фигура 1). Почти всички анкетирани са чували термина „цитонамазка“ (93\%), за мамографско изследване са чували със сигурност или с известна сигурност $86 \%$, а за тест за скрита кръв във фекалиите - 71 \%. Разпределението на лицата, които със сигурност са чували за съответното изследване е $93 \%$ за цитонамазка, $71 \%$ за мамография и 25 \% за ФОБТ.

Фигура 1. Информираност относно скрининговите изследвания за трите локализации

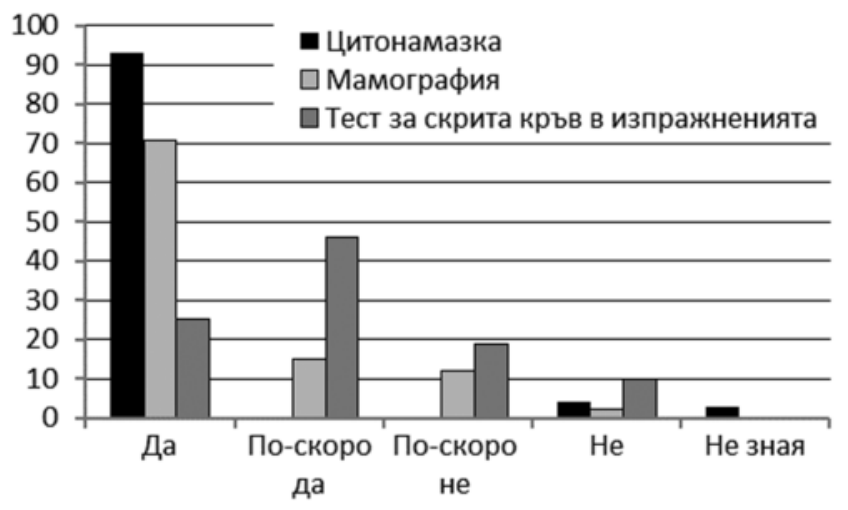

Отговорите на въпросите за цุелта на съответните изследвания показват, че и в трите групи анкетирани граждани над половината участници смятат, че посочените изследвания трябва да се правят на лица с проявени симптоми. Между 18 и $30 \%$ се разпределят отговорите, че това са профилактични изследвания. Значителен е и броят на лицата, които не знаят кога се правят съответните скринингови изследвания, като най-голям е делът на незнаещите при теста за скрита кръв.

Повече от две трети от анкетираните знаят, че открит навреме, ракът на маточната шийка е лечим, около $11 \%$ са смятат, че не могат да се предпазят или, че заболяването протича твърде бързо и цитонамазката няма да им помогне, а други 17\% нямат знание. Отговорите относно „силата“ на мамографията за предпазване от рак на гърдата, показват сравнително добро познаване на фактите. Около 2/3 от 
жените дават отговор, че мамографията може да ги предпази, защото открито навреме, заболяването е лечимо (44\%) или че мамографията няма да ги предпази, но ще помогне заболяването да бъде ранно диагностицирано (25\%). Останалите отговори се разпределят между „Не““(6\%), „Ракът се развива твърде бързо и мамографията не помага“ $(11 \%)$ и „не зная““ $(14 \%)$. Отговорите относно възможността на теста за окултни кръвоизливи да предпази от рак на дебелото черво показва, че за една трета от анкетираните тестьт е надежден и може да ги предпази, 20\% смятат, че той не е достатъчно сигурен източник на информация за заболяването, $20 \%$ - че не могат да се предпазят от рак, а 21\% нямат мнение.

Фигура 2. Знание относно изелта на мамографското изследване

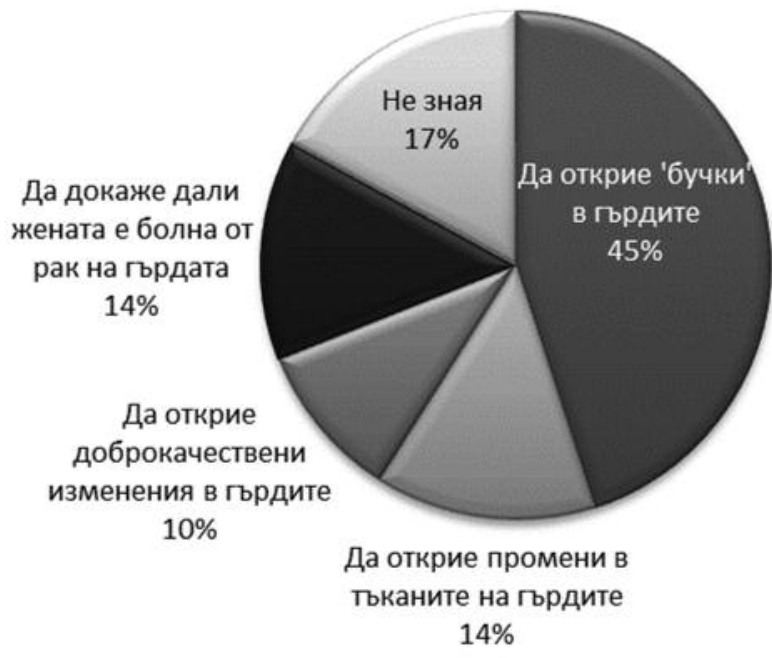

Отговорите на въпросите относно кои са подлежащите на скрининг лица показват относително адекватно знание сред анкетираните за маточната шийка. Отговорите за мамографското изследване потвърждават информацията от въпроса кога следва да се провеждат скринингови тестове, тъй като според 38 \% от анкетираните то се прави на жени с оплаквания. Останалите отговори са разпределени между това, че мамография трябва да се прави на жени с фамилна обремененост (23\%), жени над 18 годишна възраст $(14 \%)$, жени над 50 годишна възраст (16\%) и незнаещите. При анкетираните за теста за скрита крьв в изпражненията наймного респонденти смятат, че изследването следва да се прави на лицата с фамилна обремененост. Над $1 / 4$ смятат, че тестът е за лица над 18 г., по около $15 \%$ смятат, че е само за жени, съответно мъже, а 7\% - за хора с оплаквания.

Знанията относно честотата на провеждане на мамография са противоречиви - 33\% дават отговор, съответстващ на скрининговия интервал (1-2 години), 37\% смятат, че интервалът е 3-5 години, за 7\% веднъж в живота, 21\% не знаят. Относно честотата - а ФОБТ - около $1 / 3$ не знаят колко често, $11 \%$ смятат, че то се прави при наличие на болест, за 13\% е достатъчно и веднъж в живота, за 24\% интервальт е 3-5 години, за 19\% - 1-2 години, а за 6\% честотата следва да е на шест месеца. Допълнителна информация в знанията за теста за окултни кръвоизливи и целите му получаваме и от отговорите за предпочитанията на участниците относно мястото на даване на пробите за анализ. Само 7\% от отговорите са „при домашни условия“, а над 2/3 смятат, че е по-добре пробата да се даде в лечебно заведение, като поравно се разпределят отговорите за ЛЗ от доболничната и болничната помощ.

По-възрастните граждани с по-ниско ниво на образование, живеещи в по-малки населени места имат по-огра- ничени знания за скрининговите изследвания, както и определящите себе си като представители на турската или ромската общност.

\section{Информация, предоставена от медицинските специалисти}

Един от критериите за оценка на скрининговата услуга е качеството на предоставената преди извършване на процедурата информация. Запитани дали са получили от медицинските специалисти информация за същността и рисковете на съответната процедура, по-малко от половината участници отговарят утвърдително. От тях най-голям дял заемат позитивните отговори относно цитонамазките $(70 \%)$, следвани от тези за мамографията (48\%), а само един от десет от запитаните за ФОБТ е бил информиран.Прави впечатление, че броят на лицата, дали отговор „не зная“ и не далите никакъв отговор надвишава броя на далите положителен отговор.

Таблица 1. Информация, получена от медицински специалисти за същността на скрининговото изследване

\begin{tabular}{|l|r|r|r|r|r|}
\hline & $\begin{array}{c}\text { Цитона- } \\
\text { мазка }\end{array}$ & $\begin{array}{c}\text { Мамо- } \\
\text { графия }\end{array}$ & \multicolumn{1}{c|}{ ФОБт } & $\begin{array}{c}\text { Общо } \\
\text { брой }\end{array}$ & $\begin{array}{c}\text { Общо } \\
\%\end{array}$ \\
\hline Да & 70 & 48 & 10 & 128 & 42.6 \\
\hline Не & 7 & 6 & 11 & 24 & 8.0 \\
\hline $\begin{array}{l}\text { Не зная / } \\
\text { не си спомням }\end{array}$ & 10 & 18 & 35 & 61 & 20.3 \\
\hline $\begin{array}{l}\text { Брошура / } \\
\text { листовка }\end{array}$ & 1 & - & 2 & 3 & 1.0 \\
\hline Друго & 1 & 2 & 1 & 4 & 1.3 \\
\hline Липсват данни & 11 & 26 & 41 & 78 & 26.0 \\
\hline Общо & 100 & 100 & 100 & 100 & 100 \\
\hline
\end{tabular}

В допълнение и потвърждение на данните относно предоставяната от медицинските специалисти информация за скрининговите изследвания са и тези за подписването на информирано съгласие или други документи, съпътстващи процедурите. Около половината от анкетираните не са подписвали документ, информиращ ги за целите и рисковете на съответните изследвания. И ако по отношение на ФОБТ, заради малкия брой преминали през изследването, е трудно да се интерпретират данните, то за останалите две изследвания тези резултати могат да се определят като силно тревожни. Показателен е и незначителният брой позитивни отговори (под 10\%).

Отговорите за начина по който гражданите получават резултатите от изследванията си също буди тревога. Само около половината анкетирани имат ясен отговор за това как са получили резултатите си. Останалите или не са ги получили, или не са отговорили на въпроса. Добър показател е сравнително високият дял на анкетираните, които отговарят, че са обсьдили резултатите си с медицинско лице - сестра или лекар (50\%).

\section{Бариери, удовлетвореност и нагласи за явяване в бъдеще}

Личните причини на анкетираните отлагане на скрининговите изследвания са представени на Таблица 2.

Отговорите показват, че липсата на симптоми, т.е. себеоценката „Здрав съм“ е най-честата причина за отлагане и неявяване на изследване, следвано от липсата на предложение от страна на лекар. Важни системни бариери остават и ограниченията на общопрактикуващите лекари (ОПЛ) за насочване към превантивни изследвания, цената на изследванията и др. Като по-съществени персонални бариери могат да се определят неприятните усещания от прегледа, страха 
Таблица 2. Персонални бариери

\begin{tabular}{|c|c|c|c|c|c|}
\hline Отговор & \begin{tabular}{|} 
Цитона- \\
мазка
\end{tabular} & $\begin{array}{l}\text { Мамо- } \\
\text { графия }\end{array}$ & ФОБТ & $\begin{array}{l}\text { Oбщио } \\
\text { брой }\end{array}$ & $\underset{\%}{06 m 0}$ \\
\hline Липсата на време & 7 & 11 & 13 & 31 & 7.36 \\
\hline $\begin{array}{l}\text { Лекарят не ми } \\
\text { е предлагал }\end{array}$ & 20 & 9 & 35 & 64 & 15.20 \\
\hline $\begin{array}{l}\text { Не зная към кого да } \\
\text { се обърна и кака е } \\
\text { процедурата }\end{array}$ & 1 & 21 & 15 & 37 & 8.79 \\
\hline $\begin{array}{l}\text { Посещенията при } \\
\text { лекаря са неприятни }\end{array}$ & 24 & 2 & 25 & 51 & 12.11 \\
\hline $\begin{array}{l}\text { Страх от лоша диаг- } \\
\text { ноза }\end{array}$ & 11 & 12 & 12 & 35 & 8.31 \\
\hline $\begin{array}{l}\text { Цената на изследва- } \\
\text { нето е висока }\end{array}$ & 3 & 9 & 6 & 18 & 4.27 \\
\hline $\begin{array}{l}\text { Не мисля, че ще ми } \\
\text { обърнат внимание, } \\
\text { ако отида само за } \\
\text { това }\end{array}$ & 3 & 14 & 25 & 32 & 7.60 \\
\hline $\begin{array}{l}\text { Здрав/а съм и нямам } \\
\text { нужда }\end{array}$ & 34 & 14 & 33 & 81 & 19.23 \\
\hline Не съм отлагал/а & 16 & 6 & 5 & 27 & 6.41 \\
\hline Нямам причини & 1 & 8 & - & 9 & 2.13 \\
\hline Друго & 1 & 19 & 1 & 21 & 4.99 \\
\hline Без отговор & 2 & 1 & 2 & 5 & 1.19 \\
\hline Общо & 123 & 126 & 172 & 421 & 97.59 \\
\hline
\end{tabular}

от лоша диагноза, очакването че лекаря няма да обърне внимание на желанието за изследване, липсата на време и други. Интересно е да се отбележи, че най-много отговори „Не знам към кого да се обърна“" са дали анкетираните за рак на гърдата, следвани от тези за колоректалния рак, докато само една жена е дала този отговор за цитонамазките.

Усещането, че прегледът е неприятен е съществена бариера при анкетираните за РМШ и КРР, но не и за РМЖ От анкетираните за РМЖ, само 2 жени са определили дискомфорта по време на изследването, като значителен или „в известна степен“. Аналогично, само по две жени са определили болката при прегледа като съществена и са изпитали усещане за нарушени лични граници. На същите въпроси за усещанията по време на взимането на цитонамазка, около една четвърт от жените отговарят, че са изпитали дискомфорт, една от десет е имала чувство за нарушени лични граници и около половината са изпитали болка.

Удовлетвореността от предоставеното качество на услугата е индикатор и за вероятността за явяване при покана в бъдеще. Данните сочат, че около половината от анкетираните не са изразили мнението си и не са дали оценка. От тези, които са отговорили, най-голяма част оценяват услугата като добра и много добра, и много малка част - като лоша или със средно качество. Предвид, че най-много действителни отговори са дадени по отношение на цитонамазките, както и че най-много участници са провеждали именно това изследване, следва да се отбележи, че около една четвърт от анкетираните за РМШ оценяват получената от тях услуга като незадоволителна (т.е. дават лоша и средна оценка). По отношение на позитивните оценки над 2/3 от действителните отговори дават добра, много добра или отлична оценка на получената услуга (70.0\%), но само $6 \%$ отговора са „отличен““. При отговорите за мамографиите, почти всички, които са дали отговор на въпроса, оценяват услугата позитивно - като „добра“ или „много добра“ (53 от 58 отговора - 91.4\%) и една жена е дала отлична оценка. Поради спецификата на мамографското изследване и по-големите рискове от провеждането му (лъчение, дискомфорт, стрес), тези позитивни оценки са особено важни.
Удовлетвореността от извършената услуга може косвено да бъде измерена и по желанието/готовността/ на лицата, преминали през съответното изследване да го направят отново на същото място. Резултатите са по-скоро позитивни, като над две трети (80\%) от далите отговор за цитонамазка и мамография биха се върнали при същия лекар.

\section{Нагласи за явяване на скринингово изследване в бъдеще}

В условия на опортюнистичен скрининг, един от найсъществените показатели при въвеждане на организиран модел е нагласата на подлежащите на скрининг лица за явяване при покана.

Нагласите могат да се оценят и чрез отговорите за готовност за явяване за изследване при препоръка от лекар и при покана от изследването от 2018 г. И в двата случая повече са позитивните нагласи, със значителни разлики спрямо трите различни изследвания. Разпределението на отговорите „Не зная“, обаче, отново показва важната роля на лекаря. Само 25 души съобщават, че не знаят дали ще отидат за изследване при препорька от лекар, докато при получаване на покана - те са 87 (около 1/3).

\section{Аискусия}

За качеството на скрининговата услуга най-голямо значение има предоствената в рамките на програмата информация, както и придържането към добри практики за достоверност, информиран избор и адекватно за потребителите съобщаване на резултатите. Получените резултати са повод за тревога, тъй като показват, че предоставяната от смятания за най-надежден източник на информация - лекарите, не е достатъчна. Особено притеснително е, че около половината от жените, подложени на мамографско изследване отговарят, че не са били информирани за изследването. Имайки предвид неговата специфика, фактът, че е свързано с обльчване и нерядко с изпитван дискомфорт, правилата за добра медицинска практика при скрининг ясно указват, че изследваните лица трябва да бъдат ясно информирани относно ползите и възможните рискове на изследването, включително и за качеството на използваната апаратура, нивата на облъчване и т.н. Данните сочат, че информацията за скрининговите тестове и възможността им да спомогнат за ранна диагностика сред групите, подлежащи на скрининг, не е достатъчна и следва да се подобри по всички възможни информационни канали.

В допълнение и потвърждение на данните относно предоставяната от медицинските специалисти иформация за скрининговите изследвания, са и тези за подписването на информирано съгласие или други документи, сьпьтстващи процедурите. Около половината от анкетираните не са подписвали документ, информиращ ги за целите и рисковете на съответните изследвания.

Следователно, можем да заключим, че на гражданите или не се предоставят за подпис информирани съгласия при тези изследвания, или им се предоставят документи с неясно за тях съдържание, което прави отговорите им несигурни.

Запазва се тенденцията жените да очакват от лекарите си да им предложат да се подложат на дадено профилактично изследване. Важни системни бариери остават и ограниченията на ОПЛ за насочване към превантивни изследвания, цената на изследванията и др. Личните/персоналните/ бариери се отнасят главно до неприятните усещания от прегледите, цената и страхът от лоша диагноза.

Ако през 2004 г. най-много от анкетираните жени са отчитали като главни бариери липсата на предложение от страна на лекаря, страхът от лоша диагноза и очакването, че искането за профилактично изследване няма да бъде удов- 
летворено, то през 2018 г. най-голям процент от отговорите засягат себеоценката за добро здраве и усещането, че прегледите са неприятни.

\section{Изводи}

Знанията сред гражданите за ролята на скрининга и скрининговите тестове все още не са достатьчни и следва да се подобряват по всички възможни информационни канали. Ниският образователен и социално-икономически статус са основни бариери за получаване на качествени скринингови услуги. Запазват се неравенствата между отделните етнически групи при достъпа до скринингови изследвания.

Сред основните системни бариери са ограниченията на ОПЛ за насочване към превантивни изследвания, цената на изследванията и др. Личните бариери се отнасят главно до неприятните усещания от прегледите, цената и страхът от лоша диагноза.

Запазва се тенденцията жените (и мъжете) да очакват от лекарите си да им предложат да се подложат на дадено профилактично изследване. Известяването чрез писмена покана е нов подход, който засега не се приема еднозначно от населението.

\section{Закиючение}

Въпреки, че в България все още не е въведена популационна скринингова програма и липсват критерии за оценка на съществуващите практики, благодарение на усилията на много експерти по темата, в последните години са проведени разнообразни проучвания и анализи, целящи описание на съвременната ситуация, нейните предимства и недостатьци, както и приложението на различни подходи за обхващане на целевите групи. Резултатите от проведеното проучване сочат, че знанията на гражданите за ролята на скрининга и различните скринингови тестове са недостатьчни и следва да се подобряват по всички възможни информационни канали. Информационните кампании, предшестващи или съпътстващи дейности по превенция/скрининг/ следва да отразяват демографските и етнически специфики. Националната информационна кампания е скъп подход, чиято ефективност следва да бъде доказана. Използването на разнообразни информационни канали като регионални медии, образователни инициативи в специфични общности (етнически, религиозни и др.), здравни медиатори и др. могат значително да повишат знанието и обхвата на скрининга.

Разпространяваната информация трябва да акцентира, че скринингът е метод за профилактика, и предлаганите изследвания са за здрави хора, а не са диагностични, за лица със симптоматика.

\section{Библиография}

1. Аврамова, Л., Александрова, А., Балабанова, Д., Брадли, Дж., Панайотова, Ю, Тодорова, И., 2005, Онкологичен скрининг за рак на маточната шийка в България: психосоциални аспекти и състояние на здравната система, Научен център „Психология и здраве” и EngenderHealth, София, 2005

2. Гергов И., Профилактична кампания за диагностика на рака на гърдата с първична мамография в подвижен мамограф - крайни резултати и хистологични потвърждения, Рентгенология и Радиология, 2016, кн.2.

3. Джафер Н, К. Докова, Нагласи за профилактика на онкологични заболявания сред жените в България, Социална медицина, 2015 (4), 8-11.

4. Димова Р., Димов Р., 2007, Отношение, нагласа и поведение на общопрактикуващите лекари при провеждането на скринингова програма за колоректален карцином. Обща медицина, 9 (3) 6-11.

5. Almog R, Hagoel L, Tamir A, Barnett O, Rennert G. Quality control in a National Program for the early detection of breast cancer: women's satisfaction with the mammography process. Womens Health Issues. 2008;18(2):110-7.

6. Arbyn M, Anttila A, Jordan J, Ronco G, Schenck U, Segnan N, et al editors. 2nd ed. European Guidelines for Quality Assurance in Cervical Cancer Screening. Luxembourg: Office of Official Publications of the European Communities, 2008.

7. Bray F, Ferlay J, Soerjomataram I, Siegel R, Torre L, Jemal A, Global Cancer Statistics 2018: GLOBOCAN Estimates of Incidence and Mortality Worldwide for 36 Cancers in 185 Countries, CA CANCER J CLIN 2018;68:394-424

8. Craciun, C., Todorova, I., \& Baban, A. (2018). "Taking responsibility for my health": Health system barriers and women's attitudes toward cervical cancer screening in Romania and Bulgaria. Journal of Health Psychology https://doi.org/10.1177/1359105318787616

9. Peipins LA, Shapiro JA, Bobo JK, Berkowitz Z. Impact of women's experiences during mammography on adherence to rescreening (United States). Cancer Causes Control. 2006;17(4):439-47.

10. Perry N, M. Broeders, C. de Wolf, S. Törnberg, R. Holland, L. von Karsa (Eds), European Guidelines for Quality Assurance in Breast Cancer Screening and Diagnosis Fourth edition, IARC, 2008.

11. Segnan N, Patnick J, von Karsa L (Editors) European Guidelines for Quality Assurance in Colorectal Cancer Screening, 1st Edition, IARC, 2012.

12. Tang TS, Patterson SK, Roubidoux MA, Duan L. Women's mammography experience and its impact on screening adherence. Psychooncology. 2009;18(7):727-34.

13. Todorova, I., Baban, A., Alexandrova, A., \& Bradley, J. (2009). Inequalities in cervical cancer screening in Eastern Europe: Perspectives from Bulgaria and Romania. International Journal of Public Health, 54, 222-232.

14. Todorova, I., Baban, A., Balbanova, D., Panayotova, Y., \& Bradley, J. (2006). Providers' construction of women's role in cervical cancer screening in Eastern Europe. Social Science and Medicine, 63(3), 776-787.

15. Valerianova Z, Panayotova Y, Amati C, Baili P, Cervical cancer screening in Bulgaria - Past and Present Experience, Tumori 2010 Jul-Aug; 96(4):53844.

16. Wilson JMG, Jungner G. Principles and practices of screening for disease. Geneva, Switzerland: World Health Organization; 1968. Report No.: Public Health Papers No. 34. http://whqlibdoc.who.int/php/ WHO_PHP_34.pdf

\begin{tabular}{l} 
Автори \\
Юлия Панайотова, МУ-София, ФОЗ, катедра „Социална медицина“ \\
Доц. д-р Лидия Георгиева, дм, МУ-София, ФОЗ, катедра „Социална медицина“ \\
\hline \hline
\end{tabular}

В бъдеще ще се види, че рентгеновите лъчи са чисто мошеничество и че радиото няма бъдеще.

$$
\begin{array}{r}
\text { Изказване на британския физик лорд Келвин } \\
\text { в края на ХІХ век }
\end{array}
$$

Няма причина, която би оправдала използването на високото напрежение и променливия ток както в научен, така и в търговски аспект.

Томас Алва Едисон, американски изобретател, 18892
Хората няма никога да се придвижат във въздуха с някакъв апарат или ракета.

Саймън Нюкъм, канадски астроном и откривател на планетата Нептун, 1903 г.

Теорията на относителността мога да я възприема също толкова малко, колкото съществуването на атомите и другите тем подобни догми.

Ернст Мах, австрийски физик, 19132. Подбрал доц. Мирчо Вуков 